\title{
Haematopoietic stem cell transplantation in South Africa: Current limitations and future perspectives
}

\author{
S Grobbelaar, ${ }^{1} \mathrm{BSc}$ (Hons); A E Mercier, ${ }^{1} \mathrm{MSc}, \mathrm{MB} \mathrm{ChB}, \mathrm{PhD}$; E Verburgh, ${ }^{2} \mathrm{MD}, \mathrm{PhD}$, D Brittain, ${ }^{3} \mathrm{MB} \mathrm{ChB}, \mathrm{FC} \mathrm{Path}(\mathrm{Haem})$; \\ M S Pepper, ${ }^{4} \mathrm{MB} \mathrm{ChB}, \mathrm{PhD}, \mathrm{MD}$ \\ ${ }^{1}$ Department of Physiology, School of Medicine, Faculty of Health Sciences, University of Pretoria, South Africa \\ ${ }^{2}$ Division of Clinical Haematology, Department of Medicine, School of Medicine, Faculty of Health Sciences, University of Cape Town, South Africa \\ ${ }^{3}$ The Alberts Cellular Therapy Centre, Netcare Pretoria East Hospital, Pretoria, South Africa \\ ${ }^{4}$ Institute for Cellular and Molecular Medicine, Department of Immunology, and SAMRC Extramural Unit for Stem Cell Research and Therapy, \\ School of Medicine, Faculty of Health Sciences, University of Pretoria, South Africa
}

Corresponding author: M Pepper (michael.pepper@up.ac.za)

The growing need for haematopoietic stem cell transplantation (HSCT) is reflected in the increasing number of transplants performed globally each year. HSCT provides life-changing and potentially curative therapy for a range of pathologies including haematological malignancies; other indications include certain congenital and acquired disorders of the haematopoietic system, autoimmune conditions and hereditary diseases. The primary goals of HSCT are either to replace haematopoietic stem and progenitor cells (HSPC) following myeloablative chemotherapy or to cure the original pathology with allogeneic HSPCs. Success depends on optimal outcomes at various stages of the procedure including mobilisation of marrow stem/progenitor cells for harvesting from the patient or donor, long-term and sustainable engraftment of these cells in the recipient, and prevention of graft-versus-host disease in the case of allogeneic HSCT. Challenges in South Africa include high cost, limited infrastructure and lack of appropriately trained staff, as well as limitations in securing suitable haematopoietic stem cell donors. This review aims to provide an overview of HSCT and some of the challenges that are faced in the South African context.

S Afr Med J 2019;109(8 Suppl 1):S47-S53. https://doi.org/10.7196/SAMJ.2019.v109i8b.13888

Allogeneic haematopoietic stem cell transplantation (HSCT) involves the transfusion of donor haematopoietic stem and progenitor cells (HSPC) procured from bone marrow, peripheral blood or the umbilical cord into a suitably primed recipient. Autologous haematopoietic stem cell transplantation, on the other hand, denotes the collection of the patient's own stem cells prior to high-dose myeloablative chemotherapy, which are subsequently re-infused as a stem cell rescue to facilitate recovery of the marrow function. HSCT was pioneered by E D Thomas in 1957. ${ }^{[1]}$ At that time, this procedure provided the first evidence that bone marrow had the capacity to regenerate the haematopoietic system and effectively treat or alleviate disorders of the same origin. Since 1957, HSCT has formed part of the treatment regimen of more than one million patients. ${ }^{[2]}$ The European Group of Blood and Marrow Transplantation (EBMT) annually conducts a survey on HSCT activity in order to observe and monitor trends in Europe and affiliated countries. Data collected by these surveys provide evidence on the growing need for this procedure, with the number of HSCTs performed annually increasing from 4234 in 1990 to over 40000 in 2017. ${ }^{[3]}$ There are no statistics currently available for the number of transplants performed in South Africa (SA), nor data reporting the need for this treatment or patient burden, and thus the deduction of an increased demand can be made on observed global trends. Schonfeld et al. ${ }^{[4]}$ reported that 14662 patients were diagnosed with haematological malignancies between 2000 and 2006, being responsible for $6 \%$ of the new cancer diagnoses and $8 \%$ of the cancer deaths reported in SA. These data were collected from the National Cancer Registry, which has certain caveats in that there may be underreporting of these cancers owing to diagnostic and reporting challenges in rural and lower socio-economic communities. A regional study conducted by Oelofse and Truter ${ }^{[5]}$ found that haematological malignancies were not uncommon in Eastern Cape Province, and the incidence was comparable to some European populations. Additionally, certain black and Afrikaner population groups of SA are at greater risk of inheriting Fanconi's anaemia owing to the genetic founder effect of the mutant Fanconi-associated genes. ${ }^{[6]}$

Indications for the procedure have expanded to encompass treatment of not only haematological and non-haematological malignancies, but also congenital and other acquired disorders of the haematopoietic system, as well as autoimmune and hereditary diseases (Table 1). ${ }^{[7]}$

Based on data collected from the World Health Organization (WHO)-defined global regions, Gratwohl et al. ${ }^{[2]}$ reported that $58 \%$ of all HSCTs performed were autologous whilst $42 \%$ were allogeneic. Furthermore, the highest number of HSCTs were performed in Europe, followed by the Americas, Southeast Asia and the Western Pacific. The lowest number of HSCTs were performed in Eastern Mediterranean countries and Africa. Additionally, HSCTs were not carried out in countries with populations of less than 300000 or with a gross national income less than USD1 260 per capita. ${ }^{[2]}$ These findings were attributed to the high costs associated with the procedure, limiting the availability of this treatment option in developing nations. These facts raise pertinent ethical questions regarding distributive justice, encompassing the limited access of lower socio-economic populations in sub-Saharan Africa to this treatment modality. This procedure is life-changing as it (i) counters the toxic effects of treatment regimens that are used to reduce tumour load; (ii) lengthens the time to relapse; or (iii) may potentially cure disorders (such as allogeneic HSCT for aplastic anaemia or acute myeloid leukaemia (AML)) that may otherwise prove fatal. 
Table 1. Pathologies in which either autologous and/or allogeneic HSCTs may be indicated

\begin{tabular}{ll}
\hline Disorder & Autologous HSCT \\
\hline Haematological malignancies & $\begin{array}{l}\text { Acute myeloid leukaemia } \\
\text { Multiple myeloma } \\
\text { Primary amyloidosis } \\
\text { Acute lymphoblastic lymphoma } \\
\text { Hodgkin's lymphoma } \\
\text { Non-Hodgkin's lymphoma }\end{array}$ \\
& \\
Other haematological disorders & Multiple sclerosis \\
Autoimmune diseases & $\begin{array}{l}\text { Systemic lupus erythematosis } \\
\text { Crohn's disease } \\
\text { Rheumatoid arthritis }\end{array}$
\end{tabular}

Hereditary disorders

Fanconi anaemia

Sickle cell anaemia

Thalassaemia major

Wiskott-Aldrich syndrome

Diamond-Blackfan anaemia

HSCT = haematopoietic stem cell transplantation

In a single-centre study, Remberger et al. ${ }^{[8]}$ reported a $70 \%$ 3-year overall survival rate in patients who received HSCT for a range of pathologies. Svenberg et al. ${ }^{[9]}$ reported an overall survival rate of $82 \%$ for malignant and $96 \%$ for non-malignant disorders in paediatric patients 5 years after receiving the HSCT. As technology and skill have improved in the HSCT field, mortality rates have dropped from $82 \%$ between 1992 and 2000 to $46 \%$ by the end of 2009 as a composite for all eligible pathologies. ${ }^{[8]}$

Therapeutic success of the procedure depends on successful mobilisation of HSPCs from the marrow (either the patient's marrow or a suitable donor), long-term and sustainable engraftment of the transplanted cells, and the prevention of graft-versus-host disease in the case of allogeneic HSCT.

\section{Haematopoietic stem and progenitor cells}

Embryonic haematopoiesis begins in the yolk sac and continues in the aorta-gonad-mesonephros region as well as at multiple other locations throughout gestation. ${ }^{[10]}$ Adult haematopoiesis occurs predominantly in the bone marrow and may include extramedullary locations such as the liver and spleen. ${ }^{[1]}$ HSPCs are multipotent cells responsible for the production and maintenance of all blood cell lineages. ${ }^{[12]}$ These self-renewing cells firstly differentiate into common myeloid (CMP) and common lymphoid (CLP) progenitor cells (Fig. 1). ${ }^{[10]}$ The adult HSPC niche (micro-environment that protects and sustains HSPC development, mobilisation and homing) is located in bone marrow along endosteal surfaces of trabecular bone in close proximity to endothelial cells. The latter allows for gaseous diffusion and nutrient movement between the intravascular compartment and the niche. ${ }^{[13]}$

\section{Haematopoietic stem cell transplantation}

The essential component of HSCT is the HSPCs which can be collected directly from bone marrow, peripheral blood through apheresis or umbilical cord blood. ${ }^{[14]}$ Guidelines set out to identify and enumerate HSPCs were consolidated in 1996 by the International Society of Hematotherapy and Graft Engineering (ISHAGE), ${ }^{[15]}$ recently renamed the International Society for Cell and Gene Therapy (ISCT). These guidelines remain the gold standard. HSPCs are identified and enumerated based on expression of the CD34 surface protein and the dimly expressed common leukocyte antigen CD45. ${ }^{[15]}$ HSPCs are also characterised by the absence of lineagespecific markers.

The HSCT procedure may be divided into several stages, as illustrated in Fig. 2. ${ }^{[16]}$ The fundamental principle behind HSCT in haematopoietic maligancy is the administration of HSPCs after myeloablative treatment, with the aim of having the donor stem cells home to their niche in the bone marrow to regenerate the haematopoietic system (stem cell rescue).

\section{Disease-specific selection of patients for transplant and eligibility for transplant}

HSCT is indicated as a primary treatment modality in patients diagnosed with various pathologies, or as second-line therapy when conventional protocols have failed or are ineffective (Table 1). Patient suitability is determined by several physiological and pathological factors (Table 2). These include cardiac, hepatic, pulmonary and renal function evaluations, viral and other infection screens, and the determination of the comorbidity index score. ${ }^{[17]}$ Failure to meet these criteria may be seen as relative contraindications, as they may be superseded by expert opinion based on advances in medication, supportive care and technology.

HSCT is subject to identification of a suitable source for the acquisition of stem cells. In the case of autologous HSCT, a patient's stem cells may not adequately mobilise into the peripheral circulation, yielding inadequate numbers to proceed with the protocol. Allogeneic HSCT may not be feasible if there are no available donors. The latter constitutes a particular challenge in the South African setting, and is highlighted later in this article.

\section{Mobilisation}

To facilitate harvesting, HSPCs are released from their marrow niche into the peripheral circulation by mobilisation. Mobilisation occurs when neutrophils, activated by granulocyte colony-stimulating 


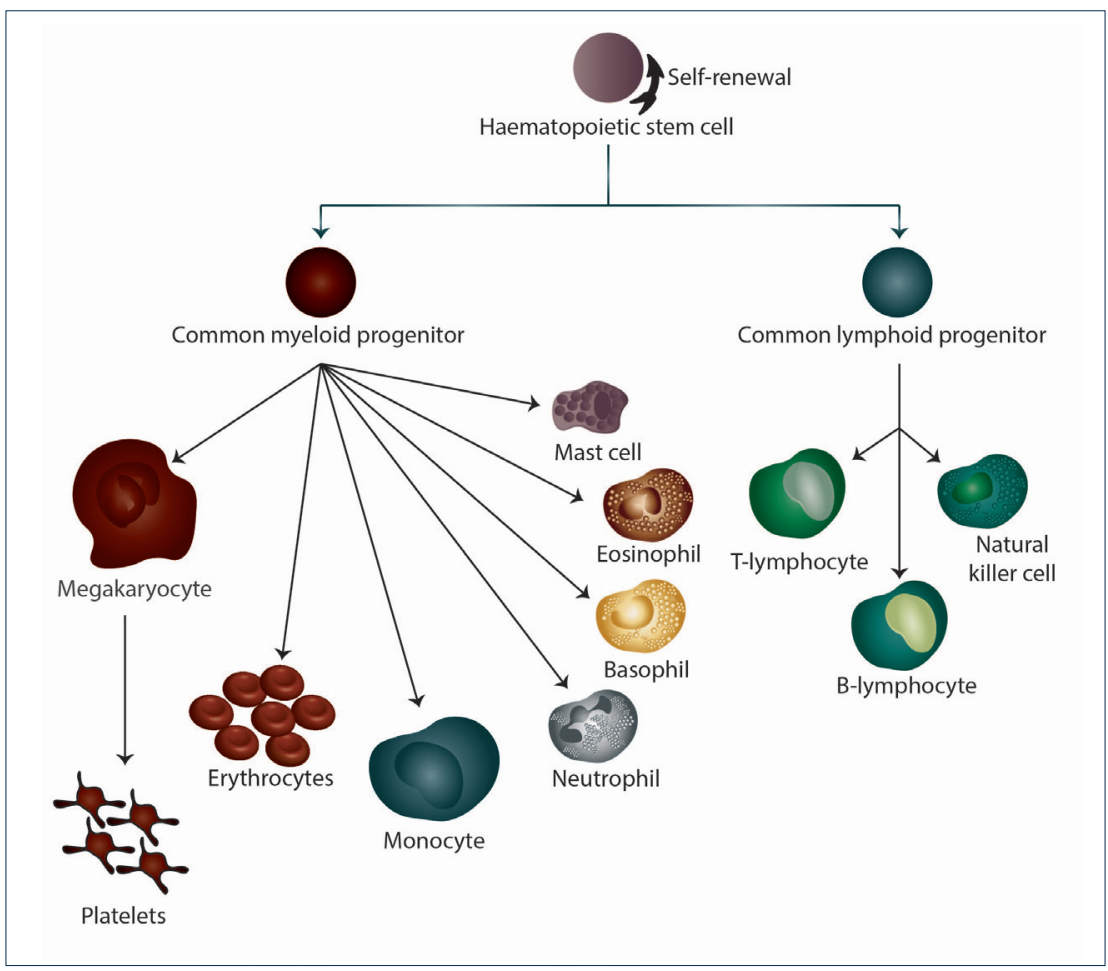

Fig. 1. Schematic representation of haematopoiesis. Haematopoiesis is the process during which the various blood cells are produced and regenerated. Multipotent haematopoietic stem cells have the ability to self-regenerate and subsequently differentiate into two distinct cell lineages, myeloid and lymphoid. The common myeloid progenitor differentiates into platelet-forming megakaryocytes, erythrocytes, monocytes, neutrophils, eosinophils, basophils and mast cells. The common lymphoid progenitor differentiates into T- and B-lymphocytes and natural killer cells).

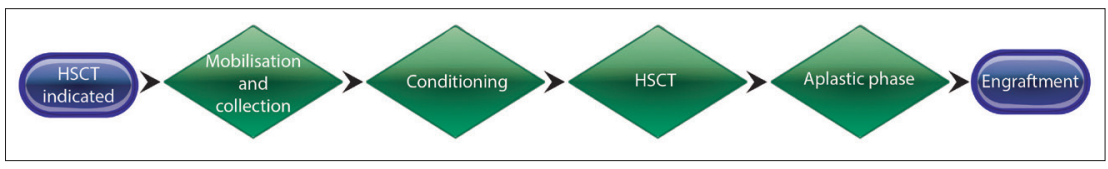

Fig. 2. The sequence of haematopoietic stem cell transplantation (HSCT) in haematopoietic malignancies. Once haematopoietic stem cell transplantation is clinically indicated, stem cells are mobilised from their marrow niche using medical mobilising agents in either the patient (autologous) or a suitable donor (allogenic). Haematopoietic stem and progenitor cells are harvested, most commonly by apheresis. The conditioning phase encompasses treatment with high-dose chemotherapeutic agents and/or total body irradiation with the aim of achieving myeloablation. This is followed by infusion of the donor stem cells. The aplastic phase in which patients do not have a functional haematopietic system lasts between 10 and 20 days during which they are nursed in protective isolation until engraftment is achieved. Thus the desired outcome is a patient with a fully functioning haematopoietic system without the initial pathology).

factors (G-CSF), release proteolytic enzymes such as elastase and cathepsin G. These enzymes cleave the terminal amino sequence of stromal cell-derived factor-1 (SDF-1) attached to the $\mathrm{C}-\mathrm{X}-\mathrm{C}$ chemokine receptor type 4 (CXCR-4) on HSPCs which tether the stem cells to their marrow niche. ${ }^{[18]}$ $\mathrm{G}-\mathrm{CSF}$ is the agent most frequently used for mobilisation as a single agent in allogeneic donors. Autologous stem cell collection requires that the patient concurrently receives a chemotherapeutic agent such as cyclophosphamide, as this augments the number of mobilised $\mathrm{CD} 34^{+}$cells. $^{[19]}$
$10^{6} \times \mathrm{CD} 34^{+}$cells $/ \mathrm{kg}$ predicts a satisfactory harvest yield. ${ }^{[21]}$

\section{Factors influencing autologous haematopoietic stem and progenitor cell mobilisation}

Factors which have been linked to poor HSPC mobilisation in autologous stem cell donors include advanced age, prior radiation and malignant infiltration. Exposure to purine analogues (fludarabine), alkylating agents (melphalan) and immunomodulators (lenalidomide) has also been associated with a negative prediction of mobilisation..$^{[22]}$ 'Proven' poor mobilisers are characterised by circulating $\mathrm{CD} 34^{+}$cells peaking at less than $20 \mathrm{CD}^{+} 4^{+}$cells/ $\mu \mathrm{L}$ up to 6 days after mobilisation with G-CSF alone, up to 20 days after G-CSF in combination with chemotherapy, or if there is a yield of less than $2.0 \times 10^{6} \mathrm{CD} 34^{+}$cells $/ \mathrm{kg}$ collected with 3 apheresis attempts. ${ }^{[23]}$ 'Predicted' poor mobilisers have a history of previously failed collection attempts, have had prior treatment with chemotherapeutic or radiation regimens that affect HSPC mobilisation, and if any two of the following criteria are met: advanced disease treated with more than 2 lines of chemotherapy, refractory disease, extensive bone marrow infiltration, marrow cellularity less than $30 \%$ at the time of mobilisation, or age $>65$ years (Table 3). ${ }^{[23]}$

\section{Factors influencing allogeneic donor suitability}

Eligibility of donors largely depends on matching human leukocyte antigen (HLA) alleles, which are heterogeneous between individuals and races. Donors for allogeneic transplants may be sourced either from consenting family members (HLA-matched related donors if they have identical HLA alleles, or haploidentical if they have halfmatched HLA genotypes) or from unrelated HLA-matched donors (non-familial). Finding a suitable donor remains a challenge for many patients. The odds of finding an HLA-matched related donor is approximately 1 in 4 and this depends on family size and structure. This drops significantly (as low as 1 in 100 000) when the search extends to HLA-matched unrelated donors. The HLA genes are located on chromosome 6 and are some of the most polymorphic genes in the human genome, resulting in large variability of expression. ${ }^{[24]}$ Pertinently, the SA population is genetically highly diverse in respect to HLA alleles, particularly in people of African descent. ${ }^{[25]}$ Although certain HLA 


\begin{tabular}{|c|c|}
\hline Parameter & Recommendation \\
\hline \multicolumn{2}{|l|}{ General parameters } \\
\hline Maximum age & 75 years \\
\hline Karnofsky performance index & $\geq 60-70$ \\
\hline Left ventricular ejection fraction & $\geq 45 \%$ \\
\hline Heart rhythm & No uncontrolled arrhythmias \\
\hline Secondary malignancy & None evident \\
\hline Pregnancy tests & Negative \\
\hline Uncontrolled infections & Not evident \\
\hline \multicolumn{2}{|l|}{ Lung function } \\
\hline $\mathrm{FEV}_{1} / \mathrm{FVC}$ ratio & $\geq 60 \%$ \\
\hline Diffusion capacity & $\geq 50 \%$ \\
\hline \multicolumn{2}{|l|}{ Liver function } \\
\hline Serum bilirubin & $\leq 34 \mu \mathrm{mol} / \mathrm{L}$ \\
\hline ALT/AST & $\leq 2 \times$ normal \\
\hline \multicolumn{2}{|l|}{ Viral hepatitis screen } \\
\hline Negative & Preferred \\
\hline Positive & $\begin{array}{l}\text { Not an absolute contraindication, but patients with a positive screen may } \\
\text { risk viral reactivation following a HSCT }\end{array}$ \\
\hline \multicolumn{2}{|l|}{ HIV screen } \\
\hline Negative & Preferred \\
\hline \multirow[t]{2}{*}{ Positive } & HIV-positive patients with a CD4 count $>100 / \mu \mathrm{L}$ \\
\hline & A low to undetectable viral load, $<10000$ copies $/ \mathrm{mL}$ \\
\hline HCT-CI & Recommended score of $0-2$ \\
\hline
\end{tabular}

\begin{tabular}{ll} 
Table 3. Criteria that characterise 'proven' and 'predicted' poor autologous CD34 & Predicted poor mobilisers \\
\hline Proven poor mobilisers & Previous failed collection attempts \\
\hline $\begin{array}{l}\text { Circulating CD } 34^{+} \text {cell peak }<20 / \mu \mathrm{L} \text { for up to } 6 \text { days after mobilisation } \\
\text { with G-CSF alone }\end{array}$ & $\begin{array}{l}\text { Prior treatment with chemotherapeutic or radiation regimens that } \\
\text { affect HSPC mobilisation }\end{array}$ \\
$\begin{array}{ll}\text { Circulating CD } 34^{+} \text {cell peak }<20 / \mu \mathrm{L} \text { up to } 20 \text { days after G-CSF in } & \text { Two of the following criteria: } \\
\text { combination with chemotherapy } & \text { - advanced disease treated with }>2 \text { lines of chemotherapy } \\
& \text { - refractory disease } \\
\text { A yield }<2.0 \times 10^{6} \mathrm{CD} 34^{+} \text {cells } / \mathrm{kg} \text { after } 3 \text { apheresis collections } & \text { - extensive bone marrow infiltration } \\
& \text { - bone marrow cellularity }<30 \% \text { at the time of mobilisation }\end{array}$ \\
G-CSF = granulocyte colony-stimulating factors; HSPC = haematopoietic stem and progenitor cells.
\end{tabular}

alleles may be associated more frequently with particular population groups, it is the expression of uncommon population-specific alleles that further decreases the chances of identifying suitable donors, even in international registries. ${ }^{[26]}$

There are additional challenges in the South African context to providing successful HSCT to all patients in need of the treatment. HSCTs are predominantly performed in the private medical sector, which limits the access to this treatment modality to patients on higher-end medical insurance (17\% of the SA population ${ }^{[27]}$ ) or to those who have the financial means. The high cost involved in accessing international donors is therefore a limitation, owing to the same reason. ${ }^{[28]}$ The past few years have seen an increase in government-funded hospitals providing HSCT, but there is at present only one academic centre with a fully-fledged HSCT programme for allogeneic (including haploidentical) transplantation. Van Eyssen et al. ${ }^{[28]}$ assessed the outcomes of 48 state-funded children who received allogeneic HSCTs at the Groote Schuur Hospital/ University of Cape Town Private Academic Hospital transplant unit. The authors aimed to evaluate the clinical outcomes of allogeneic HSCT in order to motivate future allocation of the substantial resources required to sustain such a treatment programme in SA. The overall survival in children treated for non-oncological diseases was 91\% (median follow-up of 3.94 years) and 57\% (median follow-up of 1.86 years) for children treated for haematological malignancies. These observations were comparable to outcomes reported in highincome counterpart facilities, ${ }^{[28]}$ and justify allocating the country's limited resources to additional state-funded programmes.

Towards the aim of facilitating more equitable access to this treatment option, the South African Bone Marrow Registry (SABMR), ${ }^{[29]}$ an internationally recognised non-profit organisation endeavouring to find suitable donors for critically ill children and adults in SA, had as of 2017 recruited more than 73000 registered 
donors. The SABMR provides services to patients both locally and internationally. Their collaboration with the World Marrow Donor Association (WMDA) provides further access for patients to a database of over 32 million international donors. The SABMR is coordinating a drive to sign on more local donors in order to meet the complex requirements of SA's genetically highly diverse population more comprehensively. ${ }^{[26]}$ The Sunflower Fund ${ }^{[30]}$ is an independent not-forprofit organisation founded as a donor recruitment centre and registry. It is actively involved in the education of the population to raise awareness regarding the need for South African donors, and assists in acquiring funds for patients unable to afford the costs of the HSCT. It has created collaborations with international stem cell/bone marrow registries, including those of other African countries, such as Ghana.

In the past decade, the use of haploidentical donors has become a well-recognised and successful practice should a sibling or matched unrelated donor not be unavailable. ${ }^{[31]}$ For African and mixed-race patients, a matched unrelated donor is particularly difficult to source on any donor registry. This is due to ethnic diversity and unique genetic determinants making the likelihood of an international donor match unlikely. Additionally, there is a dearth of local volunteer donors in these population groups. The pool of suitable donors may be further restricted owing to the high prevalence of the human immunodeficiency virus (HIV) in the SA population (13.1\% according to StatsSA). ${ }^{[32]}$ A haploidentical donor from consenting first- or second-degree relatives is available immediately, and is considerably less costly to procure.

\section{Conditioning}

Preparative or conditioning regimens in haematological malignancies aim to achieve three goals: (i) to reduce tumour load (treat the underlying condition); (ii) to facilitate sufficient immunoablation to prepare a niche for new marrow formation; and (iii) to suppress immune function sufficiently to prevent graft rejection and graftversus-host disease. Conditioning is specifically tailored to each pathology and is administered either prior to or after mobilisation as well as post HSPC collection. Regimens involve combinations of multiple chemotherapeutic agents, total body irradiation (TBI), corticosteroids and other disease-specific pharmaceuticals. Conventional conditioning regimens range from myeloablative to non-myeloablative, based on the dose of chemotherapy and/or TBI. ${ }^{[33]}$ The latter encompass myeloablative and antineoplastic alkylating agents such as melphalan, busulphan and cyclophosphamide, as monotherapy or in various combinations. For example, busulphancontaining agents or fludarabine (a purine antimetabolite) may be used in combination with cyclophosphamide to reduce cyclophosphamidespecific cellular toxicity. ${ }^{[34,35]}$ The development of reduced-intensity conditioning (RIC) regimens with diminished adverse chemotoxicity while promoting immunomodulation has improved certain patient outcomes, particularly in the elderly. ${ }^{[36,37]}$ The choice to employ a specific regimen is based on the balance between immunosuppressive and myelosuppressive properties and the desired outcome in the management of the specific pathology. For instance, a combination of cyclophosphamide and 12 Gy TBI used in myeloablative regimens is highly myeloablative and immunosuppressive. Reduction of the TBI to 5.5 Gy would be classified as a reduced intensity regimen. Fludarabine, cyclophosphamide and 2 Gy TBI may be used in non-myeloablative regimens for their immunosuppressive effects. ${ }^{[38]}$ Myeloablative protocols have increased toxicity profiles and rely less on the graft-versus-malignancy (GVM) effect to eliminate residual disease. The reduced-intensity and non-myeloablative regimens are less toxic and rely more on the GVM effect to eradicate residual disease while reducing graft-versus-host interactions. ${ }^{[38]}$

\section{Engraftment}

An infusion of $2 \times 10^{6}$ harvested $\mathrm{CD}^{2} 4^{+}$cells $/ \mathrm{kg}$ is considered the minimum number of transplanted HSPCs needed to reliably ensure sustained engraftment. ${ }^{[15]}$ Engraftment success is monitored by neutrophil and platelet counts measured daily post transplant. Successful neutrophil engraftment is defined as an absolute neutrophil count of more than $0.5 \times 10^{9}$ neutrophils/L for 3 consecutive days. Platelet engraftment success is attained when the non-transfusionrelated platelet count is more than $20 \times 10^{9}$ platelets/L for 3 consecutive days. ${ }^{[39]}$ Consensus in the literature considers the number of viable $\mathrm{CD}_{3} 4^{+}$cells transplanted to be the primary indicator of engraftment success or failure, with higher numbers being associated with a more favourable prognosis.

\section{Graft-versus-host disease}

Graft-versus-host disease (GVHD) is defined as a syndrome in which immunocompetent donor immune cells react to and destroy host tissues in immunocompromised recipients. ${ }^{[40]}$ Lazaryan et al..$^{[41]}$ investigated potential risk factors and found that mobilised peripheral blood as a graft source was associated with a higher incidence of GVHD. Advanced recipient age was associated with a higher incidence of acute and chronic GVHD. Furthermore, conditioning regimen intensity appears to have an influence, with non-myeloablative conditioning regimens increasing the risk for acute GVHD. ${ }^{[41]}$ GVHD is initiated by tissue damage induced by the chemotherapeutic regimen prior to the transplant, and is intensified as $\mathrm{T}$ cell activation and clonal proliferation orchestrate cytokines, chemokines and direct cellular toxicity in an exaggerated imflammatory reaction. ${ }^{[42]}$ Damage-associated molecular patterns (DAMPs) lead to the activation of host antigen presenting cells (APCs). The activated APCs subsequently present host antigens to the donor's $\mathrm{T}$ cells, resulting in the release of pro-inflammatory cytokines that include tumour necrosis factor- $\alpha, \gamma$-interferon and interleukin (IL)-1 and IL-12, which exacerbate tissue damage. ${ }^{[43]}$

Acute GVHD presents during the treatment phase with involvement of the skin, liver and gastrointestinal tract. Diverse clinical presentations include exfoliative and/or ulcerative dermatitis, liver dysfunction, and severe vomiting and diarrhoea. ${ }^{[4]}$ The mechanisms involved in the pathophysiology of chronic GVHD remain unclear. ${ }^{[45]}$ Cells and cytokines associated with chronic GVHD include $\mathrm{CD}^{+} \mathrm{T}$ cells, $\mathrm{CD}^{+} \mathrm{T}$ cells and IL-1/6/10. ${ }^{[46]}$ Chronic GVHD may develop without a history of, or clinically diagnosed, acute GVHD. ${ }^{[45]}$ Onset of chronic GVHD occurs roughly 100 days post transplantation, and involves the skin, mucous membranes including the vulva and/or vagina and mouth, liver, kidneys, heart and eyes. Symptoms and signs may include erythema, dermal and subcutaneous sclerosis, oedema, cytopenia, nephrotic syndrome, liver dysfunction, exocrine pancreatic insufficiency and cardiomyopathy. ${ }^{[44]}$

First-line treatment for acute GVHD includes corticosteroids either as monotherapy or in combination with other agents such as cyclosporine, with the starting dose being dependent on the clinical severity. ${ }^{[4]}$ Second-line treatments for steroid-refractory chronic GVHD may include extracorporeal photopheresis (ECP) or immune modulators such as methotrexate, rituximab and mycophenolate mofetil. ${ }^{[47]}$ Serotherapy encompasses antibodies that target $\mathrm{T}$ cells and other immune cells that would theoretically modulate GVHD intensity. Agents such as antithymocyte globulin and alemtuzumab, a monoclonal antibody to CD52, have shown promise in prophylaxis and/or treatment of this complication, but absence of unequivocal long-term benefits, a lack of consensus on treatment regimens and their own unwanted effects render these treatments of little benefit 
in steroid-refractory GVHD currently. ${ }^{[47]}$ Alemtuzumab effectively reduces the frequency and severity of GVHD owing to its capacity to deplete competent donor T cells, and can be used as GVHD prophylaxis. ${ }^{[4]}$ Most SA centres employ this GVHD preventive agent. Immune-suppressing drugs such as tacrolimus, sirolimus, cyclophosphamide, methotrexate and mycophenolate mofetil may also be used in prophylaxis regimens.

A desirable phenomenon known as the GVM effect, may occur as donor T cells recognise and destroy residual malignant cells within the recipient. GVM is observed in allogeneic HSCT. ${ }^{[49]}$ A potential strategy to utilise this effect therapeutically may be through the use of T-regulatory cells (Tregs; also known as T-suppressor cells). Tregs develop in the thymus and function as important immune modulators of self-tolerance. ${ }^{[50]}$ Patients infused with Tregs have a lower risk of developing GVHD. ${ }^{[51,52]}$ Infusions of mesenchymal stromal cells, found in various tissues including the bone marrow, have also been used successfully to reduce the occurrence of GVHD. ${ }^{[53,54]}$ These treatments are still experimental and more research is needed to define their physiological mechanisms and respective actions.

\section{Transplant-related infections}

Transplantation-related microbial infections are a leading cause of morbidity and mortality post HSCT. Infections may be bacterial, viral and/or fungal and may vary between patients. Allogeneic HSCT patients should ideally undergo a pre-transplantation assessment of IgG antibodies to syphylis, toxoplasmosis and specific viral diseases to identify the potential risk of disease re-activation. Syphilis, tuberculosis, Toxoplasma gondii and hepatitis B and C viruses may persist for life after primary infection and can be reactivated post HSCT. ${ }^{[55]}$ Viral infection post HSCT is commonly caused by cytomegalovirus, and less commonly by human herpes virus-6, parainfluenza virus, varicella zoster virus, respiratory syncytial virus and herpes simplex virus. Viral prophylaxis post HSCT may include aciclovir, valacyclovir or valganciclovir. Of these, aciclovir is used most frequently. ${ }^{[56]}$ Invasive fungal infections include Candida, Aspergillus, Mucorales and Pneumocystis jirovecii. Fluconazole, voriconazole or posaconazole may be prescribed as prophylaxis. The prophylaxis for $P$. jirovecii includes trimethoprim-sulfamethoxazole, dapsone or atovaquone. ${ }^{[56]} \mathrm{HIV}$ is not a contraindication for HSCT and antiretroviral therapy may be continued post-transplantation if the toxcitity permits. ${ }^{[5]}$ Bacteraemias are caused by Gram-positive bacteria (such as coagulase-negative Staphylococci, Enterococci) and Gramnegative organisms such as Pseudomonas aeruginosa. ${ }^{[56]}$ Antibiotic prophylaxis, as with ciprofloxacin, has been demonstrated to effectively reduce the incidence of Gram-negative sepsis, provided the microbiological resistance profile is favourable. ${ }^{[55]}$

\section{New frontiers in allogeneic transplantation}

The emergence of RIC regimens has moved the upper age limit of myeloablative transplantation well past the 55-year cut-off formerly used for myeloablative regimens. Likewise, the barrier to performing haploidentical transplantation has been removed by utilising posttransplant cyclophosphamide to prevent graft failure and graftversus-host disease. ${ }^{[57]}$ Two South African challenges in providing HSCTs are the high incidence of HIV in potential donors, as well as the genetic diversity of the population, which reduces the probability of finding a matched unrelated donor in local or international registries. Over the past 3 years, haploidentical HSCT has been successfully implemented in South African centres for patients with no recourse to fully matched sibling or volunteer donors.

\section{Conclusion}

With the increasing need for HSCT, it remains a challenge to establish and adequately staff HSCT programmes, particularly in the state healthcare setting in SA. This leads to implicit rationing of healthcare, whereby only patients in proximity to, or referred to HSCT centres, have access to this life-changing medical procedure. With improved treatment algorithms and increased survival rates following HSCT, there will be an additional need for infrastructure and skills required for long-term follow-up programmes post HSCT $^{[58]}$ It is essential that all these factors are considered in policy making and planning to ensure ethical and equitable allocation of resources. Key objectives to achieve public-private parity of HSCT services include an increase in the number of clinical haematologist training posts and government support for establishment of fully resourced HSCT centres in every province. This task will also include raising the profile of HSCT in SA by advocacy based on haematological treatment successes as well as the creation of sustainable pathways to care. These endeavours will be advanced by the establishment of a national reporting body to determine the number of HSCTs performed in SA on a yearly basis. The data, however, would not provide an accurate representation on the definitive need of our population, as they would be biased toward patients with access to existing stem cell services and would be affected by demographic and financial constraints. Challenges in the diagnosis and reporting of pathologies, particularly in rural and resource-poor communities, will need to be addressed. To mitigate the population-specific genetic variability present in HLA-genes, recruitment of donors especially from African and mixed-race population groups is encouraged by the SABMR. However, the prevalence of HIV, and the high migration rate in SA make acquiring volunteer donors challenging. Haploidentical transplantation is a necessary tool that has to be implemented by every HSCT centre in SA to ensure equitable and affordable access to HSCT for all patients, but especially for the ethnic subpopulations where other donor pathways are limited. Favourable outcomes have been observed with haploidentical transplantation, and this may offer a suitable alternative in the absence of fully matched suitable donors,. Not-for-profit organisations such as the Sunflower Fund aim to recruit 100000 donors of African ancestry by 2030 as part of the Stem Cell Registry Alliance (SCRA), and increase education and awareness in our population.

The benefits of HSCT are undeniable as it remains one of the only curative options for a variety of haematological pathologies, thereby decreasing morbidity and mortality in affected patients. In the coming years, we need to examine and improve upon the local systems in place regarding HSCT so that we can address the lack of access to HSCT in the majority of the population. The ultimate aim would be to establish a sustainable and cost-effective model to allow all South Africans in need of this intervention to have access to the required facilities.

\section{Acknowledgements. None}

Author contributions. SG: first author, initial drafting of the manuscript and substantial editing thereafter; AEM: co-author, substantial contribution to the drafting and editing of the manuscript; EV: co-author, substantial contribution to the editing of the manuscript; DB: co-author, substantial contribution to the editing of the manuscript; MSP: substantial contribution to the editing of the manuscript.

Funding. This research was funded by the South African Medical Research Council in terms of the SAMRC's Flagship Award Project (SAMRC-RFAUFSP-01-2013/STEM CELLS), the SAMRC Extramural Unit for Stem 
Cell Research and Therapy, and the Institute for Cellular and Molecular Medicine of the University of Pretoria.

Conflicts of interest. None.

1. Thomas ED, Lochte Jr HL, Lu WC, et al. Intravenous infusion of bone marrow in patients receiving radiation and chemotherapy. N Engl J Med 1957;257(11):491-496. https://doi.org/10.1056/ nejm195709122571102

2. Gratwohl A, Pasquini MC, Aljurf M, et al. One million haemopoietic stem-cell transplants: A retrospective observational study. Lancet Haematol 2015;2(3):91-100. https://doi.org/10.3410 /f.726040527.793530721

3. Passweg JR, Baldomero H, Basak GW, et al. The EBMT activity survey report 2017: A focus on allogeneic HCT for nonmalignant indications and on the use of non-HCT cell therapies. Bone Marrow Transplant 2019. https://doi.org/10.1038/s41409-019-0465-9

4. Schonfeld SJ, Erdmann F, Wiggill T, et al. Hematologic malignancies in South Africa 2000 - 2006: Analysis of data reported to the National Cancer Registry. Cancer Med 2016;5(4):728-738. https:// Analysis of data reported to
doi.org/10.1002/cam4.597

5. Oelofse D, Truter I. Incidence of haematological malignancies, Eastern Cape Province; South Africa, 5elofse D, Truter I. Incidence of haematological malignancies, Eastern Cape Province; Sou
2004-2013. Cancer Epidemiol 2018;53:166-171. https://doi.org/10.1016/j.canep.2018.01.016

6. Feben C, Wainstein T, Kromberg J, Essop F, Krause A. Fanconi anaemia in South Africa: Past, presen and future. S Afr Med J 2018;108(5):393-398. https://doi.org/10.7196/samj.2018.v108i5.13004

7. Sureda A, Bader P, Cesaro S, et al. Indications for allo- and auto-SCT for haematological diseases, solid tumours and immune disorders: Current practice in Europe, 2015. Bone Marrow Transplant 2015;50(8):1037-1056. https://doi.org/10.1038/bmt.2015.6

8. Remberger $\mathrm{M}$, Ackefors $\mathrm{M}$, Berglund $\mathrm{S}$, et al. Improved survival after allogeneic hematopoietic stem cell transplantation in recent years. A single-center study. Biol Blood Marrow Transplant 2011;17(11):1688-1697. https://doi.org/10.1016/j.bbmt.2011.05.001

9. Svenberg P, Remberger M, Uzunel M, et al. Improved overall survival for pediatric patients undergoing allogeneic hematopoietic stem cell transplantation - a comparison of the last two decades. Pediatr Transplant 2016;20(5):667-674. https://doi.org/10.1111/petr.12723

10. Seita J, Weissman IL. Hematopoietic stem cell: Self-renewal versus differentiation. Wiley Interdiscip Seita J, Weissman IL. Hematopoietic stem cell: Self-renewal versus difter
Rev SystBiol Med 2010;2(6):640-653. https://doi.org/10.1002/wsbm.86

11. Ho MSH, Medcalf RL, Livesey SA, et al. The dynamics of adult haematopoiesis in the bone and bone 1. Ho MSH, Medcalf RL, Livesey SA, et al. The dynamics of adult haematopoiesis in the bone an
marrow environment. Br J Haematol 2015;170(4):472-486. https://doi.org/10.1111/bjh.13445

marrow environment. Br J Haematol 2015;170(4):472-486. https://doi.org/10.1111/bjh. 13445
12. Weiskopf K, Schnorr PJ, Pang WW, et al. Myeloid cell origins, differentiation, and clinical implications. 2. Weiskopf K, Schnorr PJ, Pang WW, et al. Myeloid cell origins, differentiation, and clin
Microbiol Spectr 2016;4(5). https://doi.org/10.1128/microbiolspec.mchd-0031-2016

13. Zhang J, Niu C, Ye L, et al. Identification of the haematopoietic stem cell niche and control of the niche size. Nature 2003;425(6960):836-841. https://doi.org/10.1038/nature0204

14. Copelan EA. Hematopoietic stem-cell transplantation. N Engl J Med 2006;354(17):1813-1826. https:// doi.org/10.1056/nejmra052638

15. Sutherland DR, Anderson L, Keeney M, et al. The ISHAGE guidelines for CD34+ cell determination by flow cytometry. J Hematother 1996;5(3):213-226. https://doi.org/10.1089/scd.1.1996.5.213

16. Saccardi R, Gualandi F. Hematopoietic stem cell transplantation procedures. Autoimmunity 2008;41(8):570-576. https://doi.org/10.1080/08916930802197776

17. Hamadani M, Craig M, Awan FT, et al. How we approach patient evaluation for hematopoietic stem cell transplantation. Bone Marrow Transplant 2010;45(8):1259-1268. https://doi.org/10.1038/bmt.2010.94

18. Kopp H-G, Avecilla ST, Hooper AT, et al. The bone marrow vascular niche: home of HSC differentiation Kopp H-G, Avecilla ST, Hooper AT, et al. The bone marrow vascular niche: home of HSC differen
and mobilization. Physiology 2005;20(5):349-356. https://doi.org/10.1152/physiol.00025.2005

and mobilization. Physiology 2005;20(5):349-356. https://doi.org/10.1152/physiol.00025.2005
19. Tuchman SA, Bacon WA, Huang L-W, et al. Cyclophosphamide-based hematopoietic stem cell mobilization before autologous stem cell transplantation in newly diagnosed multiple myeloma. J Clin
matic Apher 2015;30(3):176-182. https://doi.org/10.1002/jca.21360

20. Yuan S, Wang S. How do we mobilize and collect autologous peripheral blood stem cells? Transfusion 2017;57(1):13-23. https://doi.org/10.1111/trf.13868

21. Tiwari AK, Pandey P, Subbaraman H, et al. Autologous peripheral blood stem cell harvest: Collection efficiency and factors affecting it. Asian J Transfus Sci 2016;10(1):93-97. https://doi.org/10.4103/09736247.164273

22. Tekgündüz E, Arat M, Göker H, et al. Autologous hematopoietic progenitor cell mobilization and collection in adult patients presenting with multiple myeloma and lymphoma: A position-statement from the Turkish Society of Apheresis (TSA). Trans Apher Sci 2017;56(6):845-849. https://doi. org/10.1016/j.transci.2017.11.025

23. Mohty M, Hübel K, Kröger N, et al. Autologous haematopoietic stem cell mobilisation in multiple myeloma and lymphoma patients: A position statement from the European Group for Blood and myeloma and lymphoma patients: A position statement from the European Group for Blood and
Marrow Transplantation. Bone Marrow Transplant 2014;49(7):865-872. https://doi.org/10.1038/ Marrow Tra

24. The South African Bone Marrow Registry. The Development of Bone Marrow Transplantation in South Africa. http://www.sabmr.co.za/wp-content/uploads/2009/07/P-Ruff.pdf (accessed 20 November 2018

25. Mellet J, Gray CM, Pepper MS. HLA typing: Conventional techniques v. next-generation sequencing. S Afr Med J 2015;106(1):88-91. https://doi.org/10.7196/samj.2016.v106i1.9571

26. Tshabalala M, Mellet J, Pepper MS. Human leukocyte antigen diversity: A Southern African perspective. J Immunol Res 2015;2015:1-11. https://doi.org/10.1155/2015/746151

27. Statistics South Africa. General Household Survey 2017. http://www.statssa.gov.za/publications/ P0318/P03182017.pdf (accessed 20 November 2018)

28. Van Eyssen A, Hendricks M, Davidson A, et al. Single-centre experience of allogeneic haemopoietic stem cell transplant in paediatric patients in Cape Town, South Africa. S Afr Med J 2017;107(3):232238. https://doi.org/10.7196/samj.2017.v107i3.11313

29. The South African Bone Marrow Registry. The South African Bone Marrow Registry 2017 Annual Report. https://sabmr.co.za/newsite/wp-content/uploads/2018/11/AR-2017-FINAL-16-Oct_.pdf Report. https://sabmr.co.z
(accessed 20 November 2018).
30. The Sunflower Fund. https://www.sunflowerfund.org/ (accessed 13 March 2019).

31. Bashey A, Zhang X, Sizemore CA, et al. T-cell-replete HLA-haploidentical haematopoietic transplantation for haematologic malignancies using post-transplantation cyclophosphamide results in outcomes equivalent to those of contemporaneous HLA-matched related and unrelated donor transplantation. J Clin Oncol 2013;31:1310-1316. https://doi.org/10.1200/jco.2012.44.3523

32. Statistics South Africa. Midyear Population Estimates 2018. https://www.statssa.gov.za/publications/ P0302/P03022018.pdf (accessed 13 March 2019).

33. Gyurkocza B, Sandmaier BM. Conditioning regimens for hematopoietic cell transplantation: One size does not fit all. Blood 2014;124(3):344. https://doi.org/10.1182/blood-2014-02-514778

34. Pasquini MC, Le-Rademacher I, Zhu X, et al. Intravenous busulfan-based myeloablative conditioning regimens prior to hematopoietic cell transplantation for hematologic malignancies. Biol Blood Marrow Transplant 2016;22(8):1424-1430. https://doi.org/10.1016/j.bbmt.2016.04.013

35. Katsanis E, Sapp LN, Pelayo-Katsanis L, et al. Alternative donor hematopoietic cell transplantation Katsanis E, Sapp LN, Pelayo-Katsanis $\mathrm{L}$, et al. Alternative donor hematopoietic cell transplantation
conditioned with myeloablative busulfan, fludarabine, and melphalan is well tolerated and effective against high-risk myeloid malignancies. J Pediatr Hematol Oncol 2016;38(8):e315-e318. https://doi. org/10.1097/mph.0000000000000621

36. Gay F, Engelhardt M, Terpos E, et al. From transplant to novel cellular therapies in multiple myeloma European Myeloma Network guidelines and future perspectives. Haematologica 2018;103(2):197-211. https://doi.org/10.3324/haematol.2017.174573

37. William BM, de Lima M. Advances in conditioning regimens for older adults undergoing allogeneic stem cell transplantation to treat hematologic malignancies. Drugs Aging 2013;30(6):373-381. https:// doi.org/10.1007/s40266-013-0076-x

38. Baron F, Storb R. Allogeneic hematopoietic cell transplantation following nonmyeloablative conditioning as treatment for hematologic malignancies and inherited blood disorders. Mol Ther 2006;13(1):26-41. https://doi.org/10.1016/j.ymthe.2005.09.011

39. D'Rozario J, Parisotto R, Stapleton J, et al. Pre infusion, post thaw CD34+ peripheral blood stem cell enumeration as a predictor of haematopoietic engraftment in autologous haematopoietic cell transplantation. Trans Apher Sci 2014;50(3):443-450. https://doi.org/10.1016/j.transci.2014.02.021

40. Billingham RE. The biology of graft-versus-host reactions. Harvey Lect 1966;62:21-78

41. Lazaryan A, Weisdorf DJ, DeFor T, et al. Risk factors for acute and chronic graft-versus-host disease after allogeneic hematopoietic cell transplantation with umbilical cord blood and matched sibling donors. Biol Blood Marrow Transplant 2016;22(1):134-140. https://doi.org/10.1016/j.bbmt.2015.09.008

42. Magenau J, Runaas L, Reddy P. Advances in understanding the pathogenesis of graft-versus-host disease. Br J Haematol 2016;173(2):190-205. https://doi.org/10.1111/bjh.13959
d.

43. Holtan SG, Pasquini M, Weisdorf DJ. Acute graft-versus-host disease: A bench-to-bedside update. Holtan SG, Pasquini M, Weisdorf DJ. Acute graft-versus-host disease: A b
Blood 2014:124(3):363-373. https://doi.org/10.1182/blood-2014-01-514786

44. Hymes SR, Alousi AM, Cowen EW. Graft-versus-host disease: Part I. Pathogenesis and clinical manifestations of graft-versus-host disease. J Am Acad Dermatol 2012;66(4):515. https://do. org/10.1016/j.jaad.2011.11.960

45. Holtick U, Albrecht M, Chemnitz JM, et al. Bone marrow versus peripheral blood allogeneic haematopoietic stem cell transplantation for haematological malignancies in adults. Cochrane Database Syst Rev 2014;(4). https://doi.org/10.1002/14651858.cd010189.pub2

46. Schultz K. Pathophysiology of chronic graft versus host disease. Chronic Graft-Versus-Host Disease: Interdisciplinary Management 2009;1:17-30. https://doi.org/10.1017/cbo9780511576751.004

47. Garnett C, Apperley JF, Pavlů J. Treatment and management of graft-versus-host disease: Improving response and survival. Ther Adv Hematol 2013;4(6):366-378. https://doi org $/ 10.1177 / 2040620713489842$

48. Novitzky N, Thomas V, du Toit C. Prevention of graft vs. host disease with alemtuzumab 'in the bag' decreases early toxicity of stem cell transplantation and in multiple myeloma is associated with improved long-term outcome. Cytotherapy 2008;10(1):45-53. https://doi.org/10.1080/14653240701732771

49. Gratwohl A, Sureda A, Cornelissen J, et al. Alloreactivity: The janus-face of hematopoietic stem cell transplantation. Leukemia 2017; 31(8):1752-1759. https://doi.org/10.1038/leu.2017.79

50. Edinger M, Hoffmann P, Ermann J, et al. $\mathrm{CD} 4+\mathrm{CD} 25+$ regulatory T cells preserve graft-versustumor activity while inhibiting graft-versus-host disease after bone marrow transplantation. Nat Med 2003;9(9):1144-1150. https://doi.org/10.1038/nm915

51. Brunstein CG, Miller JS, McKenna DH, et al. Umbilical cord blood-derived T regulatory cells to prevent GVHD: Kinetics, toxicity profile and clinical effect. Blood 2015:127(8):1044-1051. https://doi. org/10.3410/f.725934129.793546241

52. Di Ianni M, Falzetti F, Carotti A, et al. Tregs prevent GVHD and promote immune reconstitution in HLA-haploidentical transplantation. Blood 2011;117(14):3921-3928. https://doi.org/10.1182/ blood-2010-10-311894

53. Introna M, Lucchini G, Dander E, et al. Treatment of graft versus host disease with mesenchymal stromal cells: A phase I study on 40 adult and pediatric patients. Biol Blood Marrow Transplant 2014;20(3):375-381. https://doi.org/10.1016/j.bbmt.2013.11.033

54. Peng $\mathrm{Y}$, Chen X, Liu Q, et al. Mesenchymal stromal cells infusions improve refractory chronic graft versus host disease through an increase of $\mathrm{CD} 5+$ regulatory $\mathrm{B}$ cells producing interleukin 10. Leukemia 2015;29(3):636-646. https://doi.org/10.1038/leu.2014.225

55. Ullmann AJ, Schmidt-Hieber M, Bertz H, et al. Infectious diseases in allogeneic haematopoietic stem cell transplantation: Prevention and prophylaxis strategy guidelines 2016. Ann Hematol 2016;95(9):1435-1455. https://doi.org/10.1007/s00277-016-2711-

56. Schuster MG, Cleveland AA, Dubberke ER, et al. Infections in hematopoietic cell transplant recipients Results from the organ transplant infection project, a multicenter, prospective, cohort study. Ope Forum Infect Dis 2017;4(2):ofx050. https://doi.org/10.1093/ofid/ofx050

57. Pagliardini P, Harbi S, Furts S, et al. Post-transplantation cyclophosphamide-based haploidentical versus Atg-based unrelated donor allogeneic stem cell transplantation for patients younger than 60 years with hematological malignancies: A single-center experience of 209 patients. Bone Marrow Transplant 2018. https:// doi.org/10.1038/s41409-018-0387-y

58. Gajewski JL, LeMaistre CF Silver SM, et al. Impending challenges in the hematopoietic stem cell transplantation physician workforce. Biol Blood Marrow Transplant 2009;15(12):1493-1501. https:// doi.org/10.1016/j.bbmt.2009.08.022 